\title{
Apresentação - As interfaces entre formação de professores, a docência e o ensino-aprendizagem em países ibero-americanos
}

\author{
Jhony Alexander Villa-Ochoa* \\ Edvonete Souza Alencar**
}

O dossiê reúne artigos decorrentes de pesquisas que abordam sobre a formação de professores que ensinam matemática e os diferentes aspectos da docência em universidades ibero-americanas. A proposta de dossiê potencializa o diálogo de autores que apresentam diferentes aspectos da formação inicial e continuada.

Temos visto que nos últimos anos muitos têm sido os esforços para o desenvolvimento de investigações que contribuam com o ensino e aprendizagem em matemática. Alguns estudos, como os de Plaza e Cury (2012), apresentam levantamentos sobre as pesquisas que buscaram os equívocos mais comuns de aprendizagem da matemática ou de sua utilização como reflexão em formações continuadas no Brasil. Em se tratando da preocupação com a formação de professores, Bernadete Gatti tem sido, no Brasil, uma das pesquisadoras que veem se debruçando para compreender as dificuldades e avanços da formação inicial e continuada de professores, em específico podemos constatar parte desses resultados em seu artigo Gatti (2010). Com relação às especificidades da formação de professores que ensinam matemática, podemos citar também os esforços de investigação acadêmica de um grupo de pesquisadores coordenados por Oliveira e Fiorentini (2016).

Cabe salientar que o acesso às informações nacionais sobre as pesquisas que vêm sendo desenvolvidas para compreender o cenário do ensino e aprendizagem é maior que o de pesquisas que vêm sendo realizadas em outros países. Sabemos, ainda, que os mesmos esforços para melhorar o ensino e aprendizagem de matemática têm sido realizados por pesquisadores estrangeiros.

*Universidade de Antioquia, Medellin, Colômbia. E-mail: Jhony.villa@udea.edu.co.https:// orcid.org/0000-0003-2950-1362.

${ }^{* *}$ Universidade Federal da Grande Dourados, Dourados, Mato Grosso do Sul, Brasil. E-mail: EdvoneteAlencar@ufgd.deu.br.https://orcid.org/0000-0002-5813-8702. 
Diante do exposto, vemos a necessidade de divulgação das pesquisas que estão sendo realizadas nos diferentes países ibero-americanos sobre o ensino e aprendizagem da matemática. Este dossiê reúne levantamentos do que vem sendo produzido ou mesmo apresente propostas de reflexão sobre o ensino e a formação de professores, assim como propostas inovadoras de aprendizagem, que puderam colaborar com a investigação de todos os países e propagar o conhecimento.

Assim tivemos como objetivo apresentar pesquisas realizadas em diferentes países ibero-americanos, cujas temáticas vinculem a formação de professores que ensinam matemática com especificidades da docência.

Pretende-se com esse dossiê colaborar com a investigação dos países da Ibero-américa, além de propagar o conhecimento produzido. Para isso, apresentamos mapeamentos sobre temáticas acerca da formação de professores que ensinam matemática e sobre especificidades da docência, assim como artigos decorrentes de propostas inovadoras de aprendizagem.

A leitura dos artigos selecionados para esta publicação pretende nortear futuras investigações sobre a formação de professores e suas interfaces: docência, ensino e aprendizagem. Por tanto, esse dossiê contribuirá com a divulgação do conhecimento educacional e trará possibilidades para que novos estudos sejam realizados.

Neste contexto, o dossiê tem como artigo inicial "Perspectivas actuales de la investigación en Educación Matemática en el Perú", das autoras Flores e Neira, que apresentam perspectivas atuais de Educação Matemática no Peru. As autoras apresentam um mapeamento realizado nas pesquisas desenvolvidas na Universidade Católica do Peru, especificamente nas linhas de pesquisa tecnologias e visualização, modelagem matemática e o conhecimento didático matemático.

O segundo artigo intitulado de "Um estudo acerca da pesquisa sobre formação inicial de professores que ensinam matemática nos anos iniciais de escolarização", de Guérios e Gonçalves, apresentam o resultado de um estudo documental descritivo-analítico sobre questões investigativas e resultados apresentados pelas teses desenvolvidas nas áreas de Educação e de Ensino da CAPES que tem como foco de estudo o processo de Formação Inicial de Professores que ensinam matemática nos anos iniciais de escolarização. Guérios e Gonçalves realizaram um mapeamento sobre a formação inicial de professores dos anos iniciais do Ensino Fundamental, no período de 2001-2012, no qual analisaram os conteúdos matemáticos, os aspectos didático-metodológicos, a construção de saberes, a produção de sentidos e o estágio curricular.

Seguindo os mapeamentos, o terceiro artigo chamado "A modelagem matemática nos anos iniciais como nova perspectiva para o ensino de matemática: um 
panorama de publicações brasileiras em periódicos" (de 2009 a 2018), escrito por Villa-Ochoa, Soares e Alencar, realiza um mapeamento das investigações sobre modelagem matemática nos anos iniciais do Ensino Fundamental, no período de 2009 a 2018, no qual identificaram os objetivos, as metodologias adotadas e as respectivas atividades desenvolvidas, tendo como foco de análise como as pesquisas apresentaram as atividades tendo como proposta as perspectivas inovadoras para o ensino.

O quarto artigo intitulado "Un estudio exploratorio a las tensiones en los criterios de selección de problemas en profesores de educación primaria", escrito por Piñeiro y Vasquez, investiga como os professores chilenos selecionam as situações de problemas matemáticos. Para isso, os autores aplicaram um questionário, no qual identificaram que o modo como é realizada essa seleção influenciara as atividades desenvolvidas pelos professores em sala de aula e consequentemente nas aprendizagens realizadas pelos estudantes.

O quinto artigo, "Evaluación de la alfabetización gráfica del profesorado de Educación Básica en formación y en activo”, de Rodríguez-Alveal e Díaz-Levicoy, identifica como professores do primeiro ano da Educação Básica chilena ainda em formação e outros que já atuam na área fazem a leitura de variáveis quantitativas em atividades de alfabetização gráfica. Para isso aplicaram um questionário no qual obtiveram como resultado a evidência da dificuldade dos professores na leitura gráfica e inferiram a necessidade de formações que atendam a essas especificidades.

$\mathrm{O}$ artigo "Los profesores uruguayos ante la implementación de la Plataforma Adaptativa de Matemática para aprender y enseñar Matemática", escrito por Testa e Telleza, apresenta uma investigação qualitativa e quantitativa sobre como 105 professores utilizam a plataforma adaptativa de Matemática (PAM). $\mathrm{O}$ instrumento de pesquisa foi aplicado de maneira online e demonstraram que os docentes utilizam de maneira positiva a plataforma (PAM), pois permitem ampliar as possibilidades de ensino e aprendizagem em Matemática.

No sétimo artigo, intitulado "La interpretación de los resultados, un elemento de significado para la inferencia estadística", Vera investigou os alunos de licenciatura em Psicologia da Universidade de Huelva - Espanha, com intuito de observar como estes analisavam situações problemas sobre estatística. Observou que alguns conflitos semióticos que surgiram com o desenvolvimento do estudo, como exemplo a análise de tarefas devem ser considerados como potencializadores para a reflexão sobre como ensinar estatística nos cursos de licenciatura.

E por fim, o artigo "Práctica de enseñanza de las matemáticas: Un experimento de enseñanza con profesores colombianos en formación", de Sanchez, desenvolveu uma investigação sobre as práticas de ensino na formação 
inicial dos professores da licenciatura em Matemática. Analisou-se assim o desenvolvimento profissional desses futuros professores promovendo reflexões para possíveis mudanças formativas.

Diante do exposto, espera-se que o dossiê apresentado permita a expansão e o amadurecimento das investigações da área da formação de professores, docência e ensino aprendizagem em matemática.

\section{REFERÊNCIAS}

PLAZA, E. M.; CURI, E. Avaliação externa de Matemática: saberes e dificuldades revelados por alunos das séries iniciais do Ensino Fundamental. Revista de Produção Discente em Educação Matemática, v. 1, p. 53-63, 2012.

GATTI, B. A. Pesquisa em Educação e Formação de Professores. In: ENS, Romilda Teodora; BEHRENS, Marilda Aparecida. (Org.). Formação do Professor: profissionalidade, pesquisa e cultura escolar. 1. ed. Curitiba: Editora Universitária Champagnat, 2010, v. 1, p. 117-134.

OLIVEIRA, Ana Teresa de Carvalho Correa de; FIORENTINI, D. O lugar das matemáticas na Licenciatura em Matemática: que matemáticas e que práticas formativas? Pensar a Educação, v. 2, p. 20, 2016. 